\title{
A Segunda Guerra do Golfo - Análise teórica
}

\author{
The Second Gulf War - Theoretical approach
}

Lucas Hage dos Santos Chagas*

\section{RESUMO}

Posta sob análise à luz das teorias das relações internacionais, a decisão pela invasão do Iraque em março de 2003 nos remete ao debate entre militaristas e pacifistas quanto à utilidade e a necessidade da guerra. Uma análise política da Segunda Guerra do Golfo centra-se nos interesses de poder envolvidos. Justificativas morais e consequências políticas do conflito são objeto deste artigo, sob uma diversidade de prismas teóricos.

Palavras-Chave: teorias das relações internacionais; militaristas e pacifistas; interesses de poder.

\begin{abstract}
The decision to invade remit us to the core debates between militarists and pacifists, on the utility and the necessity of war on international relations. A politic analysis face the Second War of Gulf in terms of power interests, debating its legitimacy, and seeking the causes for the invasion. Moral justification and political consequences of the conflict are discussed in this paper, through a diversity of theoretical approaches.
\end{abstract}

Keywords: theories of international relations; militarists and pacifists; power interests.

\section{INTRODUÇÃO}

Após ultimato americano para extinção de armamentos de destruição em massa, e contra a deliberação do Conselho de Segurança da Organização das Nações Unidas (CS/ONU), no dia 19 de março de 2003, os Estados Unidos deram início à Segunda Guerra do Golfo, com bombardeios a alvos selecionados na capital do Iraque, Bagdá. Em apenas algumas semanas a cidade seria tomada e estaria desmontado o regime de Saddam Hussein.

0 pretexto era pôr fim aos referidos armamentos, acabar com a ditadura de Saddam e mitigar as ameaças terroristas que se alegava associadas ao regime. 0

\footnotetext{
* Graduando de Relações Internacionais pela Universidade de Brasília (UnB) e Direito pelo Instituto de educação Superior de Brasília (IESB). Brasília, Brasil.

Conjuntura Global, Vol. 4, n. 1, jan./abr., 2015, pp. 93-101. 
privilégio do poder militar à diplomacia é comumente apontado como característica da política externa americana; e a intervenção encontrava suporte na opinião da sociedade estadunidense, ainda ressentida dos atentados de 11 de setembro de 2001.

O fim do regime do Taliban no Afeganistão também entra na composição do quadro em que se deflagrou a Segunda Guerra do Golfo. A opinião pública norteamericana posicionava-se, no geral, favoravelmente à campanha no Iraque, o que, entende-se, deu suporte à decisão pela invasão. 0 movimento de invasão do Iraque ficou, destarte, travestido de uma nota de racionalidade, indo de encontro à persecução dos interesses norte-americanos na região. No que diz respeito a este último ponto, os interesses de poder subjacentes à decisão americana de liderar a coalizão formada para a "pacificação da sociedade iraquiana", poder-se-ia sustentar que a Segunda Guerra do Golfo corrobora um padrão estrutural existente nas relações internacionais ${ }^{1}$.

Este artigo perfaz a discussão da Segunda Guerra do Golfo sob a linha de teorias clássicas das relações internacionais. 0 acontecimento não se subsume a rigor a modelos propostos por teóricos da área; tampouco se buscou proceder este esforço. Antes, o presente trabalho busca aplicar ao episódio o movimento próprio de reflexão teórica. Colhendo na realidade concreta o animus da razão, buscam-se as causas dos fenômenos, a fim de ampliar o conhecimento da ação humana, em sua mais ampla esfera de convívio².

\section{Duas visões}

Se o militarismo ${ }^{3}$ se impunha como força distintiva da postura norte-americana ao momento da invasão, uma análise retrospectiva pode sugerir considerações diversas. Os custos humanos, financeiros e políticos decorrentes da invasão podem ser levantados numa argumentação em favor do posicionamento teórico segundo o qual as guerras, a despeito de suas origens, são inúteis para fins de prosperidade socioeconômica. ${ }^{4} \mathrm{~A}$

\footnotetext{
${ }^{1}$ Grifo nosso. Os conceitos em destaques são centrais à contribuição teórica, respectivamente, de Edward Carr (CARR, Edward Hallet. Vinte Anos de Crise (1919 - 1939). Brasília: UnB, 2001. Pp. 51-53); Hans Mongenthau (MORGENTHAU, Hans. A Política Entre as Nações. Brasília: UnB, 2003. Pp. 6-8); e Kenneth Waltz (WALTZ, Kenneth. Teoria das Relações Internacionais. Lisboa: Gradiva, [1979], pp. 95-98).

${ }^{2}$ ROCHA, Antônio Jorge Ramalho da. Relaçôes Internacionais: teorias e agendas. Brasília: FUNAG, 2002, pp. 23-27.

${ }^{3}$ Entendido aqui como a primazia da expressão bélico-militar do Estado, em contraste com o aporte de instrumentos políticos, como a diplomacia. Portanto, entendem-se separadas as searas militar e política. (Cf. MORGENTHAU; 2003; p. 52)

${ }^{4}$ ANGELL, Norman. A Grande Ilusão. São Paulo: EdUnB, 2002, pp. $22-24$.

Conjuntura Global, Vol. 4, n. 1, jan./abr., 2015, pp. 93-101. 
perenidade da ameaça terrorista e as mudanças da opinião pública ao longo da ocupação tampouco parecem dar conta de uma relação necessária entre o domínio político-militar e a estabilidade social. 5

Esta reconsideração "pacifista” centra-se nos custos ao nível do indivíduo, e argumenta que quaisquer interesses em beneficios econômicos que tenham movido a Coalizão à ocupação do Iraque não seriam senão ilusórios. 0 controle político e militar de um território não se traduziria em ganhos à sociedade americana, conquanto a ocupação envolveria gastos de monta em defesa e controle da ordem civil iraquiana. ${ }^{6}$

Sob enfoque militarista, contudo, a posição da política externa americana, na decisão pela invasão do território iraquiano, não deve ser criticada sob o critério exclusivo da racionalidade. Nesta perspectiva, a política "concreta" é construída num movimento constante de informação do poder pela moral e pela ética, e se traduz em interesses particulares que não são pautados necessariamente pela razão e tampouco harmonizam-se naturalmente. ${ }^{7}$

Estes dois posicionamentos teóricos, o pacifismo e o militarismo, pairam sobre um embate de visões. No centro da discussão, a utilidade e a necessidade das guerras. Há divergência quanto às forças que compelem os Estados (os estadistas) à decisão por soluções militares. 0 enfoque militarista entende que soluções militares são sempre possibilidades pertinentes e não implicam em um abandono da política - e da razão. ${ }^{8} \mathrm{De}$ maneira diversa, o posicionamento pacifista entende que opções militares estão fora do campo político, e escapam, portanto, do meio pelo qual a política se realiza: escapam à $\log o s$, à razão. ${ }^{9}$

Se há divergência entre militaristas e pacifistas quanto à utilidade, ou quanto a inevitabilidade da guerra, pouca controvérsia resta quanto aos seus efeitos imediatos. Mostra-se mesmo pertinente o questionamento da plausibilidade dos termos "vencedores" e "vencidos" diante das perdas, gastos, esforços implicados por todos os envolvidos. ${ }^{10}$ A despeito dos motivos e da utilidade da invasão do Iraque em 2003, era patente o custo implicado, sobretudo pra população civil iraquiana.

\footnotetext{
${ }^{5}$ Idem., pp. 21-22.

${ }^{6}$ Idem., pp. 24-26.

${ }^{7}$ CARR, Edward Hallet. Vinte Anos de Crise (1919 - 1939). Brasília: UnB, 2001, pp. 91-92; 105-106.

${ }^{8}$ Menciona-se, aqui, a célebre consideração de Clausewitz, para quem a guerra não era senão a continuação da política por outros meios. (In MORGENTHAU; 2003, p. 152).

${ }^{9}$ MORGENTHAU, Hans. A Política Entre as Nações. Brasília: UnB, 2003, p. 52

${ }^{10}$ WALTZ, Kenneth. Man, the State and War. New York: Columbia University Press, 2001 [1959], p. 01.

Conjuntura Global, Vol. 4, n. 1, jan./abr., 2015, pp. 93-101. 


\section{Da legitimidade}

A aceitação da invasão do Iraque pela população americana leva, por vezes à equívoca caracterização do movimento militar como "legítimo". O suporte da opinião pública nacional, entretanto, diz respeito antes ao exercício do poder norte-americano no plano doméstico. Entendido como controle das mentes e ações dos homens pelos homens, o poder político norte-americano, sob tal alegação, é exercido sobre sua própria população. ${ }^{11}$

Nesta perspectiva, quando se limita a análise à política doméstica norteamericana, tornam-se pertinentes considerações em termos de legitimidade do poder. Internamente, o controle político sobre a população americana justifica-se moral e legalmente, sendo influente nas mentes e ações de seus alvos. ${ }^{12}$ Deste modo, o poder nacional cumpriria um papel instrumental ao firmar laços de lealdade na sociedade, sem os quais a política externa não seria exequível. ${ }^{13}$

Quanto ao exercício estrito do poder, em termos militares, a tentativa de sujeição sem qualquer justificação moral ou legal, não há de ser tomada por legítima, inobstante este seja o alinhamento dos discursos oficiais. Caberia antes centrar-se na busca dos interesses norte-americanos com a invasão do Iraque, definidos estes em termos de poder político. A invasão do Iraque pelos Estado Unidos em 2003, extrapolaria os limites da política ao fazer uso da força física. Estando separadas as esferas política e militar, o abandono dos meios políticos, discursivos, resultaria, pois, ineficiente na persecução do interesse norte-americano de ampliar seu poder. ${ }^{14}$

Em perspectiva sistêmica, a política internacional, anárquica, não comporta qualquer titularidade de autoridade pública capaz de legitimar a invasão do Iraque. Em contraste com o ambiente político doméstico, no plano internacional, a inexistência de um princípio hierárquico impossibilita qualquer forma de aproximação do poder à noção de autoridade moral ou legal. ${ }^{15}$

\footnotetext{
${ }^{11}$ MORGENTHAU, Hans. A Política Entre as Nações. Brasília: UnB, 2003, p. 51.

${ }^{12}$ MORGENTHAU, Hans. A Política Entre as Nações. Brasília: UnB, 2003, pp. 54-55.

${ }^{13}$ Idem., pp. 199-200.

${ }^{14}$ Idem., pp. 6-8; 52-54.

${ }^{15}$ WALTZ, Kenneth. Teoria das Relações Internacionais. Lisboa: Gradiva, [1979], pp. 159-162.

Conjuntura Global, Vol. 4, n. 1, jan./abr., 2015, pp. 93-101.
} 


\section{Justificativa do interesse nacional}

Em pronunciamento presidencial, logo após as primeiras movimentações do exército norte-americano, George W. Bush fez referência a valores democráticos e liberais, que foram apresentados como aspirações morais universais, no intuito justificar a invasão do Iraque sob o ponto de vista ético:

[...] Nós entramos no Iraque com respeito a seus cidadãos, sua grande civilização e às crenças religiosas que praticam. Não temos ambições no Iraque, a não ser remover uma ameaça e restaurar o controle do poder a seu próprio povo $^{16}$. [...] Nós defenderemos nossa liberdade. Nós traremos liberdade ${ }^{17}$ para os outros. E nós venceremos. ${ }^{18}$

A apresentação moral universalizada de aspirações políticas nacionais é apontada como uma tentação natural das nações, e cumpriria o papel de obscurecer os interesses de poder que conduzem as relações entre os Estados. A análise política, sob esta abordagem, deve proceder-se dentro do domínio político autônomo. ${ }^{19}$

A identificação de um universalismo, assente numa hierarquia de valores, julgados legítimos ou ilegítimos, enseja esta ideia de exportação valorativa. 0 presidente dos Estados Unidos à época fez inúmeras referências à invasão do Iraque como uma missão a ser cumprida em prol do bem da humanidade, com o que a Coalizão levava ${ }^{20}$, via ocupação militar, a democracia e a liberdade, valores liberais do ocidente. Esta lógica se desenvolve entre estratos distintos de um sistema-mundo moderno. ${ }^{21}$

É este Sistema-mundo que se distingue pelo abismo interposto entre a realidade e o plano das justificativas. Não apenas distintos, o pacifismo e o militarismo chegam mesmo a opor-se entre os discursos universalizastes e as posturas assumidas pelos atores da cena internacional. Os Estados Unidos investiriam a si próprios na função de disseminação de "valores superiores", promotores da paz, da igualdade. No entanto, esta

\footnotetext{
${ }^{16}$ Grifo nosso.

${ }^{17}$ Grifo nosso.

18 Trecho do discurso de George W. Bush. Disponível em: http://www1.folha.uol.com.br/folha/mundo/ult94u53194.shtml.

${ }^{19}$ MORGENTHAU, Hans. A Política Entre as Nações. Brasília: UnB, 2003. Pp. 21-22.

${ }^{20}$ Grifo nosso.

${ }^{21}$ WALLERSTEIN, Immanuel. The inter-State structure of the modern world-sistem. In International theory: positivism and beyond, editado por Steve Smith, Ken Booth, Maresia Zalewski. Columbia University Press. Pp. 87-98.

Conjuntura Global, Vol. 4, n. 1, jan./abr., 2015, pp. 93-101. 
moralização cria - ou explica - a necessidade do exercício do poder político-militar, que resulta, em regra, no aprofundamento de desigualdades no mundo. ${ }^{22}$

\section{Saddam Hussein, a sociedade iraquiana e as relações internacionais}

Os interesses e consequências políticas da invasão americana do Iraque devem ser buscados na análise da realidade concreta, uma vez que a justificação da orientação da política externa americana, na questão iraquiana, não deixou expressas senão motivações morais, ou acusações precariamente lastradas na realidade, como viriam pôr em prova as inspeções que se seguiram ao controle do país invadido.

As alegações em justificativa à mobilização das tropas para a invasão, em 2003, estavam centradas no caráter extremado do ditador Saddam Hussein (1); no cerceamento da liberdade civil iraquiana, por um regime tirano e belicoso (2); na ameaça internacional representada pela produção de armas de destruição em massa pelo Iraque (3). ${ }^{23}$

Saddam Hussein, líder político do Iraque pelo partido Ba'ath, estava sendo cada vez mais hostilizado pelo ocidente. Ao ditador imputou-se a simpatia a grupos terroristas, como a Al-Qaeda, fundada e chefiada por Osama Bin Laden; o uso desmedido de armas químicas contra a população iraquiana; a proximidade com o Islã, sobretudo a partir da Primeira Guerra do Golfo, em 1991, quando não faltaram referências à religião. Em síntese, o líder iraquiano era apresentado como dotado de um caráter fundamentalista e ameaçador, enquanto atentatório de valores sacramentados no mundo ocidental.

Outra imagem buscava no regime político do país invadido os elementos que desencadearam a guerra. 0 caráter ditatorial do Estado, de tendências totalizadoras e antidemocráticas, era visto como o principal elemento de ensejo da invasão liderada pelos Estados Unidos. As violações à liberdade e à democracia, associadas à própria organização política do Iraque, tornavam necessária uma "contrapartida pacificadora".

Uma terceira visão, centrada na perspectiva sistêmica, busca na ameaça internacional a causa da Segunda Guerra do Golfo. Esta seria compreendida sob a alegação de que o Iraque sustentava um programa hostil de desenvolvimento de armas

\footnotetext{
${ }^{22}$ WALLERSTEIN, Immanuel. European Universalism. New York: The New Press, 2006. Pp. 01-02, 06, 21.

${ }^{23}$ WALTZ, Kenneth. Man, the State and War. New York: Columbia University Press, 2001 [1959]. Pp. 39, 120$123,159-260$.

Conjuntura Global, Vol. 4, n. 1, jan./abr., 2015, pp. 93-101. 
químicas, biológicas e nucleares, de destruição em massa, bem como de que havia subvenção a grupos paramilitares de patrocínio do terrorismo no mundo.

Perfazendo-se um empreendimento simétrico, portanto, podem-se buscar as motivações da invasão de 2003 no militarismo que caracteriza a personalidade política de George W. Bush (1); na lealdade nacional americana, coesa em oposição à ameaça terrorista após os atentados de 11 de setembro de 2001 (2); ou na imposição dos interesses dos Estados Unidos no controle do Iraque e projeção de poder, um vez que não encontra constrangimentos institucionais diante da anarquia internacional (3).

O presidente norte-americano, George W. Bush, alimentou a doutrina neoconservadora, que acreditava - corretamente - na supremacia militar dos Estado Unidos. Esta doutrina, indissociável da administração Bush, pode ser caracterizada por encerrar duas perspectivas clássicas na abordagem das relações internacionais: idealismo wilsoniano e realismo militarista. Ia além ao confiar na utilidade do uso da força militar para remodelar o mundo conforme os interesses norte-americanos. A George W. Bush e seu privilégio do poder militar sobre a diplomacia, do unilateralismo sobre o multilateralismo, é, criticamente, imputada a causação da invasão do Iraque em 2003.24

O enfoque na coesão da sociedade americana, na guerra global ao terrorismo, por sua vez, representa outra imagem que apresenta motivos à realização da guerra. 0 ataque sofrido - e pesadamente sentido pela sociedade civil americana em 11 de setembro de 2001 - figura entre os elementos da organização política americana que compeliriam o País à liderança da coalizão formada para invadir e ocupar o Iraque. ${ }^{25}$

$\mathrm{Na}$ imagem que se faz atenta ao sistema internacional, a inexistência de uma entidade supranacional teria tornado possível a que os Estados Unidos perseguissem, pelo uso da força militar, os seus interesses de poder na região. Ademais, a ineficiência dos organismos de deliberação multinacional, patente na realização da invasão mesmo diante da negativa do Conselho de Segurança da ONU, sustenta o elemento central desta imagem: a anarquia internacional. ${ }^{26}$

\footnotetext{
${ }^{24}$ MEARSHEIMER, John J. Hans Morgenthau and the Iraq war: realism versus neo-conservatism. 19/05/2005, p. 01.

${ }^{25}$ Idem., p. 01.

${ }^{26}$ WALTZ, Kenneth. Man, the State and War. New York: Columbia University Press, 2001 [1959], pp. 159160.

Conjuntura Global, Vol. 4, n. 1, jan./abr., 2015, pp. 93-101. 


\section{Considerações finais}

Passados doze anos da invasão do Iraque pela coalizão formada sob liderança dos Estados Unidos, persiste a justificativa moral norte-americana. A luta pela "paz e estabilidade democráticas", que tinha seu núcleo na derrubada do regime de Saddam e no controle da ordem civil iraquiana, contrasta fortemente com a realidade do país invadido. Neste ponto, reaviva-se a discussão em torno da utilidade da guerra, da capacidade dos ganhos político-militares de serem traduzidos em bem-estar social e econômico.

Os custos implicados na Segunda Guerra do Golfo foram divididos consoante as assimetrias de capacidades dos Estados envolvidos. 0 abismo que separa os objetivos alegados e os resultados obtidos com a invasão sugere um erro de orientação da política externa norte-americana - ou um acerto friamente intencionado. Pondo-se os discursos sob análise, mostrou-se equivocada a expectativa de um "transbordamento" de democracia na região do Oriente Médio, que tornava atrativa a invasão do Iraque para fins de facilitar esta exportação de valores. 27

Passando-se a uma análise mais concreta, buscam-se os interesses norteamericanos de poder $^{28}$ sobre o Iraque. 0 objetivo de controle informa a existência de interesses particulares dos Estados Unidos, movidos por valores próprios, sob o signo do propósito humanitário. Era constatável o caráter unilateral ${ }^{29}$ da invasão, traduzida no interesse de controle: empresas norte-americanas ganhavam os contratos de reconstrução do país invadido, estatais iraquianas foram privatizadas, o exército do país, dissolvido. Desde as primeiras movimentações de invasão do País, figura o tom de ocupação e controle, em contraste com discursos de intervenção e libertação. ${ }^{30}$

\section{REFERÊNCIAS}

ANGELL, Norman. A Grande Ilusão. São Paulo: EdUnB, 2002.

\footnotetext{
${ }^{27}$ MEARSHEIMER, John J. Hans Morgenthau and the Iraq war: realism versus neo-conservatism. 19/05/2005, p. 05.

${ }^{28}$ Entende-se por poder, neste ponto, a capacidade de constrangimento da ação e das convicções alheias, a capacidade de um agente de pôr outros atores em harmonia com seus interesses. (Cf. MORGENTHAU; 2003, pp. 51-52).

${ }^{29} \mathrm{O}$ caráter unilateral se traduz no relativismo dos interesses perseguidos com a determinada postura (invasão do Iraque). Inobstante serem recorrentes as alegações de cunho universalista e humanitário, entendem-se reais motivações particulares dos países invasores.

${ }^{30}$ Grifo nosso.

Conjuntura Global, Vol. 4, n. 1, jan./abr., 2015, pp. 93-101. 
CARR, Edward Hallett. Vinte anos de crise (1919-1939): uma Introdução ao Estudo das Relações Internacionais. Brasília: UnB, 2001.

MEARSHEIMER, John J. Hans Morgenthau and the Iraq war: realism versus neoconservatism. 19/05/2005.

MORGENTHAU, Hans. A Política entre as Nações. Brasília: UnB, 2003.

ROCHA, Antônio Jorge Ramalho. Relações Internacionais: teorias e agendas. Brasília: FUNAG, 2002.

WALLERSTEIN, Immanuel. European Universalism. New York: The New Press, 2006.

Immanuel. The Inter-State Structure of Modern World-System. In: SMITH, S.; BOOTH, K.; ZALEWSKI, Marysia. International Relations Theory: positivism and beyond. Cambridge: Cambridge University Press, 1996.

WALTZ, Kenneth. Man, the State and War: a theoretical analysis. New York: Columbia University Press, 1959.

, Kenneth. Teoria das Relações Internacionais. Lisboa: Gradiva, [1979]. 